\title{
Addressing the challenges of language choice in the implementation of mother-tongue based bilingual education in South Sudan
}

Tanya Spronk

Correspondence: tanya_spronk@sil.org SIL International, Juba, South Sudan

\begin{abstract}
Since the signing of the Comprehensive Peace Agreement (CPA) in 2005, the Ministry of Education, Science and Technology (South Sudan) has been working towards the implementation of a Language and Education Policy in which the mother tongue of the learner is to be used as a medium of instruction for the first three years of primary education. However, with over 63 Southern Sudanese indigenous communities listed in the Interim Constitution, over 50 living languages listed in the Ethnologue and with no recent language survey or assessment done, there are many challenges in terms of language choices for education. The Department of National Languages within the Ministry of Education, Science and Technology has addressed some of these challenges through the running of a series of workshops entitled, "Principles, Practice and Planning for Multilingual Education". This article presents a participatory planning process as well as some of the resulting principles of language choice for implementation of the language policy.
\end{abstract}

\section{空}

\section{Introduction}

When Joshua Fishman first asked the question, "Who speaks what language to whom and when?" in 1965 (pg 89), the country of Sudan had been independent for nine years, and was already embroiled in civil war (Fishman 1965). It would not be until 40 years later, with the signing of the Comprehensive Peace Agreement (CPA), that the Ministry of Education, Science and Technology, Government of Southern Sudan, (MoEST, GoSS) ${ }^{\mathrm{a}}$ would have the opportunity to implement their language policy and build a national school system, and ask the question of "who speaks what language to whom and when"?

Cognizant of the importance of language in education, GoSS adopted a language -ineducation policy which states that the mother tongue of the learner is to be used as the medium of instruction in the first three years of primary education, with English used as the medium of instruction from primary four onwards ("Education Act", 2nd Draft, Section II, 7.1,2,3; 'Education Policy of New Sudan and Implementation Guidelines', SPLM 2002). The policy also stated that each of the indigenous languages in Southern Sudan would be recognized as "national languages", and would be eligible for use as a medium of instruction in government-run schools. The Department of National Languages was established within the Directorate of Quality Promotion, School

(c) 2014 Spronk; licensee Springer. This is an Open Access article distributed under the terms of the Creative Commons Attribution License (http://creativecommons.org/licenses/by/4.0), which permits unrestricted use, distribution, and reproduction in any medium, provided the original work is properly credited. 
Inspection, Standards and Innovations in order to implement this ambitious language and education policy.

This article presents a small piece of the work that has been undertaken by the Department of National Languages in order to lay the foundations for this implementation, namely, the process of participatory language mapping in order to quickly and efficiently collect data on which languages are spoken where and for what purpose throughout South Sudan and present the resulting principles of language choice for the first phases of implementation of the language policy.

\section{Laying the foundations}

South Sudan, like most African countries, is linguistically diverse, with layers of both individual multilingualism, as well as societal multilingualism. The Interim Constitution of Southern Sudan (GoSS 2005) lists 63 distinct "Indigenous Communities", while the Ethnologue lists 53 distinct languages in the region (Lewis 2009). Stemming from a desire to promote unity in diversity, a love for their indigenous cultures and languages, and the recognition of the pedagogical advantages to using each learner's mother tongue, a language policy was adopted by the Secretariat of Education, which later became the Ministry of Education Science and Technology in 2002, and later became the Ministry of General Education and Instruction.

The language and education policy adopted by the Government of the Republic of South Sudan stipulates the learner's mother tongue be used as the medium of instruction from Primary 1 through Primary 3, with English taught as a subject. In Primary 4, the medium of instruction officially changes to English, while the mother tongue of the learner is taught as a subject through to Primary 8, the final year of Primary education. English continues as the medium of instruction through secondary school and university.

This language policy was discussed and endorsed at a Language and Education conference held in early 2012 in Juba, South Sudan, which included leaders in the field of language in education from around the world, as well as policy makers, teachers and education partners in South Sudan. Proceedings from this conference are available in the forthcoming volume, published by the British Council, entitled, "Multilingual Education in Africa: Lessons from the Juba Language-in-Education Conference, 4 - 7 March 2012".

The challenges unique to South Sudan in implementing this language in education policy remain. Due to the many years of armed conflict and political instability in South Sudan, language assessment and survey to ascertain the current linguistic situation and to answer the questions of "who speaks what language to whom and when (and where)" was impossible to carry out. Furthermore, because of the war, millions of people were displaced from their original homelands - either to different parts of South Sudan, and the Republic of Sudan, to surrounding countries such as Ethiopia, Uganda and Kenya, or to the towns. Almost 3 million people have returned to their home areas in the past five years after being displaced either internally or internationally (NSCSE 2009). No displacement goes without language contact and language shift. But up to now, information has not been collected on the status of the languages in these communities. Due to factors such as the vastness of South Sudan, the lack of infrastructure, including roads and other transportation corridors, and continuing instability in rural areas, it is nearly impossible to conduct more traditional types of language assessment and survey. 
This lack of up to date information made it very difficult for the Department of National Languages to make decisions as to how to even begin facing the challenges of the policy implementation.

In order to face these challenges, together with technical advisors from the South Sudan Group of SIL International (a non profit organization committed to "serving language communities worldwide, building their capacity for sustainable language development, by means of research, translation, training and materials development" (www.sil. org)), the Department of National Languages decided to undertake a series of workshops at the State level for training and research purposes.

\section{Principles, practice and planning for multilingual education workshops}

A ten-day workshop, called "Principles, Practice and Planning for Multilingual Education" was held in three locations, with ten invited representatives from each of the ten states of South Sudan participating. These workshops were held in three locations: Wau for participants from the four States of Greater Bahr El Ghazal (Western Bahr El Ghazal, Northern Bahr El Ghazal, Warrap and Lakes), Malakal for participants from Greater Upper Nile (Unity, Upper Nile, and Jonglei) and Maridi for those from Equatoria (Central, Eastern and Western Equatoria). Participants were selected by their respective State Ministries of Education, based on criteria including knowledge of local languages and the linguistic make-up of their State, educational level and involvement in the education sector in the State. It was hoped that there would be a variety and cross-section of language communities from each State represented. In the end, the actual number of participants from each state was as follows:

- 15 representing Upper Nile State

- 6 representing Jonglei State

- 7 representing Unity State

- 4 representing Lakes State

- 9 representing Northern Bahr El Ghazal State

- 7 representing Warrap State

- 12 representing Western Bahr El Ghazal State

- 10 representing Central Equatoria State

- 10 representing Eastern Equatoria State

- 14 representing Western Equatoria State

A total of 94 State Ministry of Education representatives, along with two representatives from education-focused NGOs, participated in the workshops. There were representatives from 30 different language communities.

The workshops were planned and facilitated by two members of the Department of National Languages as well as two technical advisors from the South Sudan Branch of SIL International.

Workshop topics included both "big picture" subjects on the pedagogical benefits of mother tongue based multilingual education and how it has been implemented in other countries around the world, practical topics of literacy teaching methodology and materials development, as well as topics specific to the South Sudanese context, 
such as the South Sudan language policy, and specific stakeholder and institutional relationships within South Sudan. Full reports of each of the three workshops can be obtained from the Department of National Languages.

While the above mentioned topics served as a foundation to building a system to implement the language and education policy in South Sudan, one of the most valuable, interesting and engaging topics of the workshop was a form of language assessment and survey in which participants collectively mapped the current language situation in their own states. At the same time, other sociolinguistic data was collected on the status of the conditions and resources needed for the implementation of multilingual education in each state.

\section{Language domains}

On the first day of the workshop, participants were introduced to the concept of language domains. In order to draw their attention to the multilingual context in which they live every day, they were asked to do an analysis of which language they use in various domains such as home and family, school, mass media, business and the market, government, and cultural and religious activities. This domain analysis also helped participants see very clearly the complex multilingual situation in South Sudan, as many of the domains required different languages, including English, Arabic and many of the South Sudanese national languages.

During the domain analysis, it also became clear that in most of South Sudan, there are, at minimum, two languages in use, each being used in different domains. Often, three or four languages are used by the same person in different domains. For example, the same person might use one or two South Sudanese languages at home, at church, in the market place, at work, plus English and/or Arabic for education and government. The challenge, then, becomes deciding which languages should be promoted for use in each of these domains, and more specifically, which languages should be chosen for development for early primary education.

An assignment was given to each of the workshop participants to collect data on the environmental, systemic and language specific resource requirements for each of the language communities in their area. Questions were developed to collect, for example, the type of information as given below:

\section{Environmental}

i. Are stakeholders aware of and supportive of current language policies in your area?

\section{Systemic}

i. Do language committees or other organizations exist in your language community?

ii. Who could be involved in language and materials development?

iii. Are there teachers trained to use the Mother Tongue? If so, where did they receive this training?

\section{Resource requirements}

i. Is there an accepted orthography?

ii. What materials exist already (i.e. ABC Books, grammar, dictionaries etc.)? 
All of the information was collected and recorded by the facilitation team from the Department of National Languages and written into the reports of each workshop for later analysis.

\section{Language mapping}

Following the domain analysis, participants were given the opportunity to map their knowledge of the linguistic situation of their states, using participatory mapping methods, as outlined by Chambers (1994) in his Participatory Rural Appraisal methods. Participatory mapping has been used to a great extent through the past decades for everything from locations of water points and sanitation, to mapping of locations of crimes in an effort to reduce the risk of victimization. Participatory mapping has also been used by indigenous communities to document their "historical and cultural association to the land" (IFAD 2009, p. 5). The facilitators of the workshops in South Sudan saw an opportunity in participatory mapping to access the knowledge of the participants themselves.

Participants worked together as state groups and were given a large piece of flipchart paper and markers. Beginning with the rural areas, they were asked to draw a map of their state, marking the areas where each language was used, and how the languages were mixed. They were asked to mark how the languages were mixed in each area according to three labels - territorial (where there are clear lines between each language area), clustering (where a particular language is spoken by a cluster of people within a larger language grouping), or integrated (where two or more languages are spoken by people who are fully integrated with each other). These labels were first introduced in South Sudan by Ian Smith, Buani Consulting.

After drafts of the maps were drawn, each state group presented their maps to the larger group for comments and feedback. Digital photos of each of the maps were taken for the Department of National Languages to keep a record of the work done, and for future reference and analysis. The original maps were given to representatives of their respective States, giving the participants ownership over their original maps (Chambers 2006).

These maps enabled both the participant representatives from the State Ministries of Education, as well as the facilitators from the Department of National Languages and SIL to better understand the language situation in each of the ten states.

\section{Questionnaires}

While the percentage of people living in urban centers in South Sudan is very low (perhaps only around $2 \%$ of the population, according to NSCSE (2004)), these towns and cities are generally composed of people from many different language communities, living side by side. Because of this complexity in the language situation in the urban areas, these urban areas were not mapped, but were analyzed through a series of questions which participants answered for each of the urban centers in their State. Participants answered questions about which languages are used in the towns, the percentage of people speaking those languages, and the languages known by children entering school. Suggestions were also collected from the participants on any common languages spoken by all urban children and which languages could be used as a medium of instruction for early primary school. 
It was clear from these questions that the majority of the children entering school did not know English before they came to school, but instead knew their own mother tongue, a different South Sudanese language which was spoken in the town as a lingua franca, a local variety of Arabic, or a combination of all of the above.

While the mapping exercise and questionnaires were effective and efficient ways to get a good overview of the language situation throughout South Sudan, they do not give a complete picture of the linguistic map. Logistically, it was not possible to get representatives from each and every language community in South Sudan to participate. It was found that some of the little-known language communities (such as the Uduk) who are known to live in South Sudan were not mentioned or were said to live in the Republic of Sudan. Further, it must also be acknowledged that some of the data is also based on the individual participants' perceptions of what constitutes a "language" or a "dialect".

Through the mapping exercise, it was also found that some languages from the Northern Bahr el Ghazal and the Equatoria regions had been left out of the list of ethnic groups which is attached to the Interim Southern Sudan Constitution. It is still necessary, and recommended in documentation of the workshops, that further participatory mapping be done to collect more detailed data from each state, county and payam (village).

\section{Development of implementation guidelines}

Following the completion of the Principles, Practice and Planning for Multilingual Education workshops, a task force was commissioned by the Undersecretary of MoEST to analyze the information collected at the workshops and to make recommendations for the way forward. The task force was composed of the Director of the Department of National Languages and two technical advisors from SIL, all of whom had facilitated the workshops, plus a member of the Central Equatoria State Ministry of Education, who had been present at the third workshop in Maridi. The result of this task force was a document called "Implementation Guidelines and National Strategy for the Southern Sudan Languages and Education Policy".

While the official policy documentation, including the Interim Constitution of Southern Sudan (GOSS 2005), Syllabus for Primary Schools (for Southern Sudan) (Secretariate of Education 2002), Education Policy of the New Sudan and Implementation Guidelines (SPLM 2002), GOSS, 2nd Draft of GOSS Education Act (MoEST 2008a, b, c), esteemed all of the languages of South Sudan as "national languages" and stated that they are, by law, allowable to be used as the medium of instruction in the formal school system, little direction has been given as to how to meet the challenges that come with a diverse multilingual situation with few obvious resources.

One could leave the policy as it is and simply say that education will be available using each and every language as the medium of instruction immediately. However, it does not take long to realize that this is simply not a practical way forward in South Sudan. While the majority of the languages in South Sudan have orthographies developed and many have basic literacy books such as $\mathrm{ABC}$ Books and $\mathrm{ABC}$ Charts (though most of these are currently out of print), few languages have the required resources in terms of trained teachers or teaching and learning materials such as graded readers and 
subject textbooks to begin immediate implementation of a full program of mother tongue education.

In recognition of this, the task force, in the Implementation Guidelines, based on data collected during the Principles, Practice and Planning for MLE Workshops, made recommendations for a phased implementation of the language policy. The Implementation Guidelines also made suggestions on how to go about making the necessary difficult decisions as to which languages and which communities are best suited for this phased implementation of the languages and education policy. While current data has not been collected, Marshall, in a report commissioned by the UNESCO Institute of Life Long Learning (Literacy, language, non-formal education and alternative learning opportunities in Southern Sudan, unpublished manuscript), extrapolates from old data and estimates that:

i. The largest 4 groups - Dinka, Nuer, Zande and Bari - together form over 65\% of the population.

ii. The largest 10 groups - Dinka, Nuer, Zande, Bari, Shilluk, Otuho, Luwo, Moru, Mandari, Didinga, Toposa - form just over $80 \%$ of the population.

iii. The largest 20 groups form over $90 \%$ of the population.

The mapping exercise and data collected during the workshops supports and correlates with the above extrapolated data.

However, because of the fact that much of the population can be educated using only ten languages, it becomes clear that the initial choice for languages for the first phase of implementation may not be as challenging as initially thought, if providing education for the majority of the population is the a priority.

\section{Language choice recommendations}

The Implementation Guidelines, based on the work done by representatives from each of the ten states of South Sudan during the workshops, acknowledge the many stakeholders who will have a role in choosing the language of education in any given school in South Sudan. The process suggested for choosing a language as the medium of instruction in the first three years of primary education in rural schools made in the Implementation Guidelines (GoSS, MoEST 2009, p. 15) takes into account these stakeholders and suggests the following steps for a phased implementation. The steps are based on MoEST setting up a national institute which will oversee the implementation of the policy, called the "Institute of National Languages" (INL). The steps for language choice, for a phased implementation, are as follows:

i. MoEST/INL will ask each state to choose one language from the state for a pilot program. It suggests that this language be a Role A language and a regional language of wider communication, but is open to reasons for an alternative choice.

ii. The state must ensure that the personnel needed for the program are in place or will be in place as soon as is possible.

iii. The languages must have an accepted and approved orthography. If there is more than one orthography (writing system) in current use, a clear decision and choice 
must be made to use one for the purposes of education. There must be consensus on this decision at the language group level as represented by the Language Committee. There should be documents available that describe the orthography to be used. Final endorsement of newly developed or a contested orthography should be given by the State Language Advisory Board.

iv. The language must have a minimal set of basic literacy materials that could be reprinted and used for teaching literacy in P1-P3 (minimally there must be at least some materials covering P1 and P2). These will form the core of materials used for the first part of the program. The initial focus in INL will not be on developing new materials, but rather on using existing ones.

a. Given the criteria above, for the first phase of implementation of the language and education policy, there will be one language chosen per state, which will most likely be one of the major languages of the state. In this way, the majority of the population will have a chance to at least begin their early education in a language that is familiar to them. Continuing to use English as a medium of instruction from P1-P3 is not one of the options given.

b. As evidenced in the data collected in the workshops, it is the schools in urban areas, where languages are more mixed, in which language choice becomes more difficult. The recommended criteria for choosing the MoI for P1-P3for mixed urban areas, in order of preference, are: choose the majority language (majority being more than 50\%). Most of the minority children will have had some exposure to this language in their environment before coming to school so the language will be familiar (GoSS, MoEST 2009, pp. 15-16).

Alongside this:

i. Teachers should give extra support and encouragement to minority children in the classroom.

ii. Minority communities should be encouraged/sup- ported to set up community/ church based (e.g. afternoons or Saturday morning) classes for teaching literacy, literature and culture relating to their language.

iii. Stream classes or schools (recommend not more than 2 streams per school). If population density allows, different schools can be assigned different languages. It is recommended that some experimental schools using language streaming be set up to explore and research their benefits and possible modalities of operation.

iv. As a last option, where areas are very mixed in terms of languages spoken (as in some urban areas), the authorities have the choice of selecting English as the MoI from P1-P3, with oral use of other languages common to the students to support learning.

Of course, other considerations, such as the amount of development of each language, the amount of existing learning material available, the number of trained teachers, writers and other necessary language development personnel, and the support and enthusiasm of a given language community for the use and promotion of their language in education, must be considered alongside the above recommendations for language choice. 


\section{Phased implementation}

It is hoped that the capacity of each of the states will continue to grow, and that in the end, every language community that desires education in their language will have the opportunity to do so.

However, as mentioned above, practicalities dictate a slower, phased implementation. The above recommendations are outlined for the first phase only. In a later, fuller implementation, the following stages are recommended in the "Implementation Guidelines and National Strategy for the Languages and Education Policy in Southern Sudan" (GoSS, MoEST 2009, p. 14)

i. The SMoE (led by the State Language Coordinator) maps the languages in the state down to the county and payam level. This mapping should also record clearly where there are functioning County Education Centres (CECs), or soon to be functioning CECs, as CECs are central to teacher training for national languages. The State Language Coordinator consults with county and payam education officials in order to obtain this information. This document should be shared with Language Officers and county and payam education officials. It should also be copied to Department of National Languages in MoEST. It should be used as a basis for implementation plans and discussions with different parties.

ii. When implementation in any language is about to start, a plan should be made by the language officer in cooperation with the state language coordinator for where the implementation will be started and how it will spread (and in approximately what time frame). Local education officials, schools and community leaders should also be consulted.

iii. This plan should be communicated to and discussed with affected schools (parents, teachers, headteachers) in the year prior to starting implementation.

iv. In the case of implementation in larger towns, final approval for the implementation plan must be given by the Commissioner for that town and the State Governor.

v. The state language coordinator should consider and discuss options for languages which currently have no established writing systems or previously developed school books with education authorities and others in those areas. The options for these groups are:

a. Choose another language known by most of the children to some degree on starting school, which is ready for implementation. This may be a regional language of wider communication.

b. Delay until their language and materials can be developed.

Building a country and its related structures and institutions is challenging. Steps have been taken to move towards a basic, phased implementation of the language policy in South Sudan. The Department of National Languages has begun training some teachers in the principles and methods of mother tongue education. Basic literacy books have been printed and distributed in three languages by the government, alongside smaller numbers of literacy books printed in other languages by SIL and other NGOs. 


\section{Conclusion}

South Sudan is a diverse multilingual context, which faces difficult decisions in the implementation of their education and language policy. Based on data collected about "who speaks what language to whom and when?" through a series of workshops which included participatory mapping exercises, domain analysis and language assessment questionnaires, the Department of National Languages in the Ministry of Education, Science and Technology has recommended several criteria and processes for language choice in any given community. With the implementation of these recommendations, the children in South Sudan will have access to an effective and quality education.

\section{Endnote}

aBefore gaining independence in 2011, South Sudan was referred to as "Southern Sudan", a semi-autonomous region within the Republic of Sudan. With independence in July 2011, South Sudan became a sovereign nation. The Ministry of Education, Science and Technology (MoEST) was also renamed, "Ministry of General Education and Instruction". The documents referred to in this paper were written before independence, under the auspices of MoEST, within the government of Southern Sudan, and will be referred to as such.

\section{Competing interests}

The author declares that she has no competing interests.

Received: 6 March 2014 Accepted: 15 July 2014

Published: 8 August 2014

\section{References}

Chambers, R. 1994. Participatory rural appraisal (PRA): analysis of experience. World Development 22(9): 1253-1268. Retrieved from https://entwicklungspolitik.uni-hohenheim.de/uploads/media/Day_4_-_Reading_text_6.pdf.

Chambers, R. 2006. Participatory mapping and geographic information systems: whose Map? Who is empowered and Who is disempowered? Who gains and Who loses? The Electronic Journal on Information Systems in Developing Countries 25(2): 1-11. Retrieved from http://www.ejisdc.org/ojs2/index.php/ejisdc/article/viewFile/238/159.

Fishman, J. 1965. Who speaks what language to whom and when? In The bilingualism reader, ed. L. Wei, 89-106. London: Routledge.

GOSS. 2005. Draft interim constitution of Southern Sudan.. Retrieved from http://www.gurtong.net/LinkClick.aspx? fileticket=|OqRv9hqgv8\%3D\&

IFAD. 2009. Good practices in participatory mapping: a review prepared for the International Fund for Agricultural Development (IFAD). Retrieved from http://www.ifad.org/pub/map/PM_web.pdf.

Lewis, M.P. 2009. Ethnologue: languages of the world, 16th ed. Dallas, Tex: SIL International. Retrieved from http://www. ethnologue.com/.

MoEST. 2008a. 2nd draft of GOSS Education Act. Juba: Ministry of Education, Science and Technology.

MoEST. 2009. Implementation guidelines and national strategy for the Southern Sudan languages and education policy (2nd Draft). Juba: Ministry of Education, Science and Technology.

MoEST. 2008b. Technical findings of MOEST principles, practice and planning of multilingual education workshop: covering states of upper Nile, unity and jonglei. Juba: Ministry of Education, Science and Technology.

MoEST. 2008c. Technical findings of MOEST principles, practice and planning of multilingual education workshop: Covering States of Central, Eastern and Western Equatoria. Juba: Ministry of Education, Science and Technology.

NSCSE. 2009. Statistical yearbook for Southern Sudan 2009. Juba: Southern Sudan Centre for Statistics and Evaluation.

NSCSE. 2004. Towards a baseline: best estimates of social indicators for southern Sudan, NSCSE Series paper 1/2004,

NSCSE and UNICEF. Retrieved from www.sudanarchive.net.

SPLM. 2002. Education Act. Education policy of the New Sudan and implementation quidelines. Nairobi: SPLM.

Secretariat of Education. 2002. Syllabus for primary schools (for Southern Sudan). Nairobi: SoE.

doi:10.1186/s13616-014-0016-z

Cite this article as: Spronk: Addressing the challenges of language choice in the implementation of mother-tongue

based bilingual education in South Sudan. Multilingual Education 2014 4:16. 